\title{
Foreword: Special issue on Alan Turing
}

\author{
Christof Teuscher
}

Published online: 10 September 2011

(C) Springer-Verlag 2011

In a little known 1948 National Physical Laboratory (NPL) report entitled "Intelligent Machinery" [3], which wasn't published until 1968 [1], 14 years after his death, Alan Turing described both connectionist ideas and genetical search. In his analogy between learning and search, he suggested that intellectual, genetical, and cultural searches may all be used to inspire mechanisms by which to achieve machine intelligence.

"There is the genetical or evolutionary search by which a combination of genes is looked for, the criterion being survival value. The remarkable success of this search confirms to some extent the idea that intellectual activity consists mainly of various kinds of search" [4, p. 23].

Turing mused that at the beginning, the connectionist machines are completely unorganized, comparable to an "infants brain." "Then, by applying appropriate interference, mimicking education [...]" [4], the machine will be organized to produce a required behavior. The idea of organizing an initially random network of neurons and connections is undoubtedly one of the most significant aspects of Turing's "Intelligent Machinery" paper. At his time, Turing was unfortunately unable to apply "genetical search" to the optimization of his unorganized machines because of the lack of computing resources.

2012 sees the centenary of Turing's birth and to join in the many celebrations [2] of his remarkable contributions to computer science and artificial intelligence, Evolutionary Intelligence decided to publish a special issue, which you now hold in your hands. The goal of this special issues

C. Teuscher $(\bowtie)$

ECE Department, Portland State University, Portland, OR, USA

e-mail: teuscher@pdx.edu was to present contributions which use simulated evolution in conjunction with other of Turing's ideas, such as his unorganized machines, to achieve artificial intelligence. This special issue features three contributed papers that very nicely fit into this goal.

In the first contribution, Orr and Martin ("Evolving A-Type Artificial Neural Networks") describe a graphbased evolutionary algorithm that allows to manipulate Turing's simplest unorganized machines to represent a given function. They evaluate their algorithm with three benchmark problems and show that it performs much better than a purely random search.

In "Using Genetical and Cultural Search to Design Unorganised Machine," Bull presents an evolutionary programming approach and a new imitation-based approach for the evolution of Turing's discrete dynamical systems. The results show that both approaches are highly competitive. The author also explored the original synchronous and an asynchronous updating scheme of the unorganized machines.

Webster, in his contribution "Alan Turing's Unorganized Machines and Artificial Neural Networks-His Remarkable Early Work and Future Possibilities," proposes an alternative solution, which does not involve the invention of new structures, to address a technical error on Turing's part. He further argues that the "genetical" search proposed by Turing is likely to yield non-intuitive results, a property that was part of Turing's initial goal of brain-like networks.

I would like to thank the contributors to this special issue, the reviewers, and the Editor-in-Chief to make this issue possible. I truly hope that the Evolutionary Intelligence readership will enjoy the collection of outstanding work inspired by Alan Turing. His long-forgotten work on unorganized machines, initially dismissed as a "schoolboy 
essay" by his advisor, is more than ever current, influential, and deeply fascinating.

\section{Christof Teuscher}

Guest editor

\section{References}

1. Evans CR, Robertson ADJ (eds) (1968) Cybernetics: key papers. University Park Press, Baltimore
2. The Alan Turing Year (2012) A centenary celebration of the life and work of Alan Turing. http://www.turingcentenary.eu

3. Turing AM (1948) Intelligent machinery. The Turing Digital Archive. http://www.turingarchive.org/browse.php/C/11

4. Turing AM (1969) Intelligent machinery. In: Meltzer B, Michie D (eds) Machine Intelligence, vol 5. Edinburgh University Press, Edinburgh, pp 3-23 